\title{
ETHICA EUDEMIA I-5: É O PRAZER ALVO DA VIDA BOA? ${ }^{1}$
}

Inara Zanuzzi (UFRGS) ${ }^{2}$

inarazanuzzi@gmail.com

Resumo: $\mathrm{O}$ artigo toma como ponto de partida a argumentação da Ethica Eudemia (EE) II, 1 que retoma os resultados dos capítulos anteriores, a saber, i) o bem supremo para os seres humanos é um fim e ii) todos julgam a sabedoria teórica, a virtude moral e o prazer, ou alguns ou todos esses, serem fins. Essas duas teses permitem a Aristóteles concluir que o bem mais desejável está na alma e a partir daí fazer uma argumentação em termos de ergon, função ou atividade característica, da alma. $\mathrm{O}$ que se pode observar, entretanto, é que se o ergon da alma pode explicar serem fins sabedoria teórica e virtude moral, o mesmo é menos facilmente defensável no caso do prazer. Com efeito, tomar o prazer como fim parece ser tomar uma satisfação subjetiva com o que quer que seja, de modo que o ergon poderia explicar a satisfação subjetiva no máximo com algumas coisas, mas não com todas. Para resolver isso, procura-se no artigo interpretar uma passagem anterior, I, 5, 1215b15-1216a10, como responsável por fazer uma restrição no domínio dos prazeres que podem contar como finalidades para o ser humano.

Palavras-chave: Aristóteles; Ética Eudêmia; prazer; ergon.

1.

Ao iniciar o capítulo II, 1 Aristóteles tem por objetivo mostrar que a felicidade é a atividade de uma vida completa ou perfeita (teleia) de acordo com a virtude completa ou perfeita (teleia) ${ }^{3}$. Já está garantido, por I, 8, que o ariston, o

\footnotetext{
1 Recebido: 05-11-2014/Aprovado: 28-11-2014/Publicado on-line: 17-02-2015.

2 Inara Zanuzzi é Professora Adjunta do Departamento de Filosofia da Universidade Federal do Rio Grande do Sul, Porto Alegre, RS, Brasil.

3 Não é claro qual o sentido de teleia, mas isto será desconsiderado por ser irrelevante para o argumento que se quer aqui discutir.
} 
bem supremo para o homem, é um fim. Introduz-se agora que o bem ou o fim deve ser da alma, porque os bens da alma são mais desejáveis (hairetôtera) do que os externos. Evidência disso é que todos julgam a sabedoria teórica, a virtude moral $^{4}$ e o prazer, ou alguns ou todos esses, serem fins.

Ora, esse último resultado foi obtido nas discussões preliminares realizadas nos capítulo 1 a 5 do primeiro livro. No capítulo 6, fez-se uma transição entre essas discussões preambulares e as seguintes, que pretendem estabelecer o dia ti, as causas ou porquês relacionadas ao bem humano. É já neste último contexto que Aristóteles defende que o fim é o supremo bem humano e que agora ele inicia a discussão sobre a felicidade.

O fato que Aristóteles diga ao iniciar II, 1 que todos julgam que um daqueles bens mencionados são fins aponta para o contexto da discussão dos capítulos 1 a 5 , pois ali discutiu-se as opiniões que se têm sobre o alvo do bem viver. No que se segue vai-se defender que aquela discussão pretendeu separar conclusivamente as opiniões verdadeiras das falsas, de modo que aqui Aristóteles esteja concernido em investigar o dia ti, o porquê, disto que é julgado nestas opiniões que são verdadeiras e foram mostradas ser verdadeiras.

Além disso, é também objetivo deste artigo resolver um problema na conexão do argumento tal como rapidamente apresentado acima. Aristóteles pretende mostrar que a

\footnotetext{
4 O termo para sabedoria teórica é phronesis, e o termo para virtude moral é aretê. Não se pretende que estas sejam as traduções mais apropriadas para estes termos, apenas a especificação clara do seu significado neste contexto. Com efeito, em 1215b1-4, foi dito que a vida filosófica "aspira à phronesis, isto é, contemplação da verdade" e que "a [vida] política aspira às belas ações (e essas são as que se originam da aretề".
} 
felicidade é atividade da alma segundo a virtude completa. Para o seu argumento funcionar, ele vai introduzir a noção de alma e a noção de ergon da alma, isto é, de sua função ou atividade característica ${ }^{5}$. $\mathrm{O}$ argumento com um pouco mais de detalhe seria o seguinte. Os bens da alma são as finalidades últimas da vida humana. Evidência disso é que todos julgam sabedoria teórica, virtude moral e prazer serem fins. Estes são de fato os fins corretos, isto é, os bens da alma que são fim. Todavia, a explicação por que são os fins é que são erga da alma e na alma o seu ergon é fim. Ora, o ergon da alma humana é atividade completa segundo a virtude completa e isto é a felicidade. Assim, é inevitável que Aristóteles possa relacionar sabedoria teórica, virtude moral e prazer ao ergon da alma humana, ainda que ele não o faça explicitamente na passagem.

O prazer, entretanto, se apresenta aqui como um problema para esta tese. Com efeito, podemos mesmo dizer que fim como prazer e fim como ergon são concepções diferentes do fim. O fim como prazer pode ser entendido como o que quer que seja que dê alguma satisfação subjetiva ao agente. Ao passo que se o fim é ergon então é a própria atividade ou seu resultado peculiar que são fins. Dessa forma, o fim como ergon introduz na noção de felicidade uma independência em relação aos gostos subjetivos do agente, já que, nesse caso, não se reduz à sua satisfação subjetiva ${ }^{6}$.

Pretende-se, então, aqui mostrar como a noção de prazer já sofreu uma limitação na discussão da parte

\footnotetext{
5 Uma discussão sobre a noção de ergon está para além dos objetivos deste artigo, que envolveria discutir em profundidade o argumento de II,1. Por esta razão, preferiu-se manter 'ergon' sem tradução.

6 Cf. Barney (2008), p.308-9.
} 
preambular de modo tal que ao fazer sua reaparição no início de II,1 ela pode ser inteiramente explicada pela noção de ergon. É só porque Aristóteles já fez uma limitação na noção de prazer na investigação preliminar das opiniões sobre o alvo do bem viver que agora ele pode fazer essa generalização em termos de ergon de modo a recolher todas as finalidades apresentadas anteriormente como boas por serem erga da alma ou relacionadas ao ergon da alma ${ }^{7}$.

2.

A passagem que quero discutir é a do capítulo I, 5, 1215b15-1216a10. Ela inicia dizendo que, sobre o alvo do bem viver, não é fácil julgar corretamente, sobretudo porque é um assunto que a todos parece fácil, a saber, o que no viver é haireton, digno de escolha ou desejável, tal que, tendo obtido isto, o seu desejo ficaria plenamente satisfeito $^{8}$.

É a necessidade de pôr um alvo para a vida, estabelecida em I,2, que nos coloca nesta busca que estamos fazendo. Aristóteles abre I, 5 dizendo sobre este alvo que a todos parece fácil dizer qual é, enquanto, na realidade, é a coisa mais difícil. Como podemos saber qual é este alvo ou ao menos que critérios apontar para ele? A sugestão de interpretação aqui é que o foco de Aristóteles neste trecho é o prazer como alvo. Com efeito, o prazer parece ser uma resposta facilmente dada por todo mundo. E é certo que

7 Como se observou, Aristóteles não tira a conclusão que sabedoria teórica e virtude moral são virtudes do ergon da alma explicitamente, mas não há dúvida de que esse seja o objetivo ou ao menos de que isso possa ser facilmente feito.

8 Saliento o 'haireton' por ser precisamente o termo com que virtude moral, sabedoria teórica e prazer são reintroduzidos em II, 1: hairetôtera. 
parece ser capaz de organizar nossa vida ${ }^{9}$, mas é também capaz de tornar nossa vida algo para o qual não falta nada, ou seja, algo que possa plenamente satisfazer nossos desejos? Na hipótese de interpretação a ser desenvolvida para o argumento que se seguirá, Aristóteles propõe um exercício de pensamento visando mostrar como o prazer por si só e sem qualificação não é capaz de satisfazer ninguém plenamente. Com 'ninguém' quer-se dizer 'nenhum de nós seres humanos'. Do modo como o argumento está sendo entendido operar, cada um deveria ser capaz de perguntar a si mesmo as questões propostas e responder negativamente, isto é, "não, nesse caso questionado, o prazer não é capaz de me satisfazer plenamente, perseguir o prazer me daria uma vida insatisfatória" ${ }^{10}$. É esta universalidade da resposta que permite separar as opiniões verdadeiras das falsas com relação ao prazer.

Admitidamente, o texto pode ser lido de forma diversa. Consideremos então, a primeira passagem a ser discutida para tentar defender a plausibilidade desta leitura.

Se não é fácil julgar corretamente acerca de muitos outros assuntos, é sobretudo difícil julgar acerca do que a todos parece ser o mais

\footnotetext{
9 No diálogo Protágoras, por exemplo, o prazer aparece como uma medida para todas as nossas ações, distinguindo-as como boas ou más. É justamente por essa capacidade de ser aplicado a todas as ações que ele é capaz de organizar a nossa vida como um todo.

10 Isso provavelmente causará discordância entre os intérpretes da passagem. Alguns dirão que o argumento só será respondido negativamente por aqueles que já não tomam o prazer como aquilo que pode satisfazê-los plenamente. Ora, se isso for assim, então o argumento não pode ter, de fato, os objetivos que estou propondo, isto é, permitir que qualquer um reconheça as limitações que têm o prazer como candidato ao posto de alvo do bem viver. Para o argumento funcionar com os objetivos pretendidos, dirão os meus objetores, é preciso que seja muito forte, pois deve conduzir alguém que toma o prazer como alvo de sua vida a negar que o prazer por si só seja capaz de satisfazê-lo plenamente, o que é precisamente o que a quem o toma como alvo acredita. A meu favor, antes de dar início à reconstrução, só posso dizer que um argumento com essa finalidade parece já ter sido tentado por Platão no Filebo. Cf. Nussbaum (1995). A interpretação da passagem também foi influenciada por Finnis, 1983, cap.2.
} 
fácil e cujo conhecimento parece pertencer a todo homem: o que na vida é desejável (haireton) e satisfaria plenamente o desejo de quem o obtivesse.

Com efeito, muitos eventos são tais que em virtude deles as pessoas desistem de viver, por exemplo, doenças, dores extremas e calamidades, de modo que, se houvesse escolha, é evidente que, ao menos em virtude dessas coisas, seria de se escolher desde o início não ter nascido. (1215b15-22) ${ }^{11}$ (Grifo meu)

A primeira coisa a destacar é a relação entre estes dois parágrafos. Eles são conectados por um 'com efeito'. O que na segunda passagem explica a primeira? Nós achamos que é fácil dizer o que é desejável na vida de modo a satisfazer plenamente o desejo de quem o obtivesse. Precisamos, no entanto, compreender melhor o que está em jogo nesta questão. Procurar delimitar o que satisfaz plenamente nosso desejo é procurar delimitar aquilo sem o qual nossa vida seria indesejável a ponto de ser preferível não vivê-la. É isso o que o parágrafo introduzido por 'com efeito' mostra: ele especifica o modo como devemos entender a questão 'o que satisfaria plenamente nosso desejo?.

Ele não faz isso simplesmente estipulando como devemos entender nossa busca. Faz isso mostrando que a vida por ela própria não é capaz de ser uma boa resposta. Se a vida fosse valiosa em si mesma, então não deveríamos querer desistir de vivê-la ou preferir não vivê-la independentemente do que se passasse nela ${ }^{12}$. $O$ fato que certas vidas preferimos não viver mostra que a vida não é por si mesma desejável, mas o é em razão das coisas que fazemos ou obtemos nela. Assim, aquilo que satisfaz plenamente nosso desejo é aquilo que na vida é capaz de

11 As traduções da Ética Eudêmia são de minha autoria conjuntamente com Raphael Zillig.

12 Whiting (2012), p.101. 
torná-la desejável de ser vivida.

Para constatar, entretanto, o que precisamente fazemos e obtemos na vida que a torna finalmente desejável de ser vivida, devemos considerar as razões para vivê-la separadamente umas das outras e na forma da completa negação dessas razões. Observe como a resposta é formulada (o trecho destacado acima): "se houvesse escolha, é evidente que, ao menos em virtude dessas coisas, seria de se escolher desde o início não ter nascido". Se abstrairmos das outras coisas de que uma vida pode ser composta, isto é, se pensarmos em uma vida composta apenas de dores, então ela não é uma que se apresenta como desejável, ao contrário, é uma que se apresenta como evitável. Uma vida desejável é, portanto, uma que contém prazer. $\mathrm{O}$ prazer é sim algo que torna uma vida desejável e uma razão para viver, porque a ideia de uma vida composta inteiramente de dores (ou seja, da negação completa do prazer) se desenha como um cenário em que escolheríamos não viver.

A radicalidade da escolha parece colocar dificuldades para essa interpretação. De fato, talvez seja possível obter uma concordância bem geral que esta não seria uma vida satisfatória, mas estariam todos dispostos a preferir não vivê-la? Essa dificuldade será ainda maior nos cenários seguintes, de modo que poderia ser mais fácil defender que não são todos os seres humanos os que prefeririam não vivê-la, mas os de bom caráter. Essa vida não seria satisfatória porque seria considerada indigna de um ser humano $^{13}$. Parece, entretanto, ao menos plausível que qualquer pessoa preferiria não viver se tivesse que escolher entre uma vida composta apenas de doenças, dores 
extremas e calamidades. Além disso, que todo mundo responda que, se a vida devesse ser apenas uma sucessão de dores, então seria melhor escolher não viver, parece ser o que o texto pretende dar a entender. Se alguém preferir viver esta vida, teria que admitir, em todo o caso, que está escolhendo uma vida menos do que satisfatória. A questão que está por trás desta é então: nós escolheríamos viver uma vida que nos parecesse uma vida não boa? Em favor de dizer que todos preferiríamos não viver uma vida não boa penso que seja aquilo que está precisamente em jogo quando temos motivações suicidas. $\mathrm{O}$ suicídio faz sentido (para adultos) na medida em que a vida vai se apresentando como uma vida não boa. Ainda assim, podemos não executá-lo i) por razões religiosas, que não vêm ao caso aqui, ii) porque temos esperança que as coisas mudem ou iii) simplesmente porque não temos coragem. A radicalidade da escolha, parece, pois, depender um tanto de termos coragem para abraçar a preferência de não viver, mas isso não me parece ser uma objeção à interpretação apresentada. Para que fosse, seria preciso mostrar que escolheríamos viver esta vida porque ela nos pareceria boa.

$\bigcirc$ resultado dessa passagem seria, então, concordarmos que ninguém escolheria uma vida sem prazer algum. Mas isso não é suficiente para concluirmos que o prazer, sozinho, é capaz de tornar nossa vida autossuficiente, faltando em nada, completamente satisfatória. Mostrar isso é o propósito das passagens seguintes. Existem várias experiências prazerosas e que, todavia, uma vida constituída apenas delas não satisfaria ninguém, nem mesmo aquela pessoa que escolhe o prazer como o alvo único em sua vida. Assim, a passagem como um todo teria por consequência mostrar que há conflito entre essas duas posições: 
reconhecer que experiências prazerosas por si mesmas não resultam em uma vida plenamente satisfatória e que o prazer seja o alvo do bem viver (o que corresponde precisamente a dizer que ele é aquilo que satisfaz plenamente o desejo de alguém). No entanto, não temos por que supor que uma pessoa que coloca-se o prazer como único alvo tenha clareza de que isso está em conflito com outras coisas que ele quer também além do prazer. É por isso que Aristóteles teria dito ao começo que a resposta parece fácil, mas é de fato difícil. O prazer é uma resposta fácil para o alvo, mas errada, porque está em conflito com o que as próprias pessoas que o colocam como alvo esperam de uma vida satisfatória, ainda que elas não se deem conta disso até que um experimento desse gênero lhes seja proposto $^{14}$.

O segundo cenário diz que ninguém escolheria viver sem sair da infância (1215b22-24). Existem prazeres relacionados à infância, são chamados prazeres infantis, paidia, são prazeres do divertimento e do relaxamento. Alguém poderia imaginar, portanto, uma vida composta de diversão como uma vida completamente satisfatória. Querer levar uma vida inteira dedicada à diversão é como querer retroceder à infância. Devemos observar que existem de fato pessoas que levam a vida assim. A questão é saber se mesmo essas pessoas pensariam que teriam uma vida satisfatória, quando confrontadas com a perspectiva de ser sua vida inteiramente constituída apenas desses prazeres.

\footnotetext{
14 Se passar por esse experimento pode realmente alterar a vida das pessoas que tomam o prazer como alvo é uma outra questão. Conferir a posição de Filebo, no diálogo platônico de mesmo nome, que prefere dormir ao longo de todo diálogo, enquanto Protarco se encarrega de defender a posição por ele. É possível que outras coisas tenham que ser dadas para que passar por um tal experimento seja eficaz na prática. Assim, do ponto de vista prático, ele tem um alcance limitado, mas suficiente para os fins da investigação na ética.
} 
Isso seria como jamais deixar a vida da criança. Ainda que concedamos, para fins de argumentação, que uma tal pessoa tenha apenas experiências prazerosas, é difícil imaginar quem, em sã consciência, como diz Aristóteles ("eu phronôn"), escolheria viver esta vida antes do que simplesmente não vir a ser, pois ela assemelha-se a de uma pessoa com deficiência mental. Por mais sem seriedade que seja, uma tal pessoa teria que admitir que a vida que sustenta desejável é uma que se completa na infância, antes de se ter atingido maturidade intelectual ou emocional. Pode a vida de alguém que jamais atinge a maturidade intelectual ou emocional ser uma vida plenamente satisfatória? É difícil imaginar alguém, por mais sem seriedade que seja, que pudesse dizer que esta vida tem condições de satisfazer plenamente o que ela mesma espera.

O cenário seguinte é apresentado assim:

Além disso, (1) muito do que não traz qualquer prazer ou dor ou (2) do que traz prazer, mas não um que seja belo, é tal que torna o não ser melhor do que o viver. (3) Em geral, se alguém reunisse todas as coisas que fazem e experimentam todos, mas nenhuma delas voluntariamente (por não ser em razão dela própria), e se aplicasse uma quantidade ilimitada de tempo, não se escolheria, com vistas a essas coisas, antes viver do que não viver. (1215b24-30)

É possível entender que, nos cenários apresentados, embora o agente deseje e tenha interesse pelas coisas propostas, a vida que resulta é uma em que ele não as obtém. Assim, o que ocorre é que ele é sistematicamente frustrado em obter coisas desse gênero e a questão é saber se essa vida é satisfatória. No primeiro cenário, ele obtém apenas coisas indiferentes do ponto de vista do seu prazer e dor, no segundo, apenas coisas indiferentes do ponto de vista de sua virtude e, no terceiro cenário, apenas coisas 
absolutamente indiferentes, no sentido que não levam a nada que ele dê valor por si mesmo. Nesta interpretação, todo agente deveria reconhecer que se sentiria frustrado e de uma frustração suficientemente importante para que preferisse não levar esta vida.

No primeiro caso, se estivéssemos diante de uma vida em que tudo o que tivéssemos a escolher fosse daquelas coisas que não geram nem prazer nem dor, teríamos uma vida composta de coisas (atividades, buscas) que em si mesmas não teriam traços positivos ou negativos com relação à sensação do prazer/dor. Prazer e dor são traços do que é buscável e evitável. Se estivéssemos a lidar com coisas que não tivessem traços diferenciados por prazer e dor, estaríamos a lidar com coisas indiferentes. É difícil imaginar que pudéssemos nos sentir motivados a viver um tal tipo de vida.

No segundo caso, trata-se de uma vida que tem prazeres, mas nenhum deles é belo, admirável ou elogiável. Por que neste caso não podemos ter uma vida satisfatória e plena e por que isso deveria ser admitido por qualquer um? Nesse ponto, eu só posso tentar oferecer uma interpretação muito especulativa com o objetivo de conceber algo que deva ser aceito por qualquer pessoa, seja ela virtuosa ou não. Pareceria que alguém que não é virtuoso não está comprometido em dar algum valor a prazeres associados a coisas belas, muito menos a ponto de preferir não viver em lugar de viver, caso não possa desfrutar de prazeres desse gênero. Há, no entanto, algo distintivamente humano a respeito dos prazeres belos. Seres humanos são capazes de distinguir atividades, ações, coisas em geral de acordo com sua virtude. Isto significa tomá-las por si mesmas, como fins, e considerá-las sob o aspecto da perfeição que 
alcançam enquanto aquele tipo de coisa. Prazeres associados a virtudes, portanto, são distintivamente humanos e estão associados claramente a i) finalidades e ii) à forma de obtenção e realização dessas finalidades. A ideia seria, portanto, a de imaginar um tipo de vida em que tudo é desprovido ou frustrado nessa forma de avaliação e deste tipo de satisfação, aquela relativa ao bem fazer de certas atividades ou ao bem agir, enfim, às excelências em geral. Confrontado com essa perspectiva, quem escolheria viver essa vida? Essa parece ser uma vida, por assim dizer, amesquinhada. Que muitas ou mesmo a maioria das pessoas não organizem sua vida em função da virtude é admissível. Mas será possível realmente para alguém não reconhecer que uma vida sem a noção mesma de virtude é insatisfatória para si?

No último caso, imaginemos uma vida em que nada fosse buscado por si, nada pudesse receber uma dignidade por si mesmo, mas sempre se devesse buscar algo em razão de terse que alcançar outra coisa e isso em função de outra e isso por um tempo ilimitado, pois, claro, se se imaginasse que o tempo fosse limitado poder-se-ia dizer que tudo havia sido feito para chegar finalmente ao ponto último. Nesse caso, não seria possível jamais atingir uma satisfação completa. Isso parece tornar cada uma das coisas feitas sem sentido e, nessa medida, indiferentes. Afinal, não há nada para se obter através do buscar fazê-las. Não ser capaz de estabelecer uma finalidade última equivale a não ter a própria vida sob controle, não ter autonomia sobre ela. Não será isso razão de grande frustração a ponto de se preferir não viver?

No cenário seguinte, diz Aristóteles:

$\mathrm{Na}$ verdade, ninguém preferiria viver pelo prazer apenas da comida ou do sexo, tendo sido excluídos os demais prazeres que o conhecer 
ou o ver ou algum dos outros sentidos dá aos seres humanos, a menos que fosse um completo escravo. Com efeito, é evidente que àquele que fizesse essa escolha em nada diferiria nascer animal ou humano. Tanto é que o boi venerado no Egito como Ápis, em muitas de tais coisas é mais abastado do que muitos monarcas" (1215b30-1216a2).

Neste cenário, devemos imaginar uma vida em que todo o prazer obtido é corporal. Neste caso, como nos outros, para o exercício ter o efeito necessário, isto é, para ele convencer qualquer um de quanto uma vida deste gênero não se apresenta como uma vida desejável, é preciso pensá-la radicalmente desprovida de todos os prazeres de um certo tipo. Os prazeres que Aristóteles quer afastar são aqueles provenientes de alguma satisfação cognitiva. $\mathrm{O}$ objetivo aqui, na interpretação oferecida, é obter o reconhecimento de que as cognições têm valor intrínseco e a elas estão associados certos prazeres que não seriam corretamente intitulados 'corporais', mesmo que fossem sensíveis.

Aristóteles diz que pessoa alguma reconheceria ser preferível viver uma vida satisfazendo-se apenas de prazeres corporais, a menos que fosse um completo escravo. "Completo" talvez queira dizer: ele não seria um escravo por suas condições externas, mas porque ele próprio se coloca nesta condição. Ele próprio se coloca na condição de alguém que usufrui limitadamente da vida. Aristóteles explica a seguir porque essa escolha não seria feita senão por alguém que fosse um escravo no seu modo de ser. É que essa pessoa estaria escolhendo a vida de um boi e não a vida de um ser humano. Ao introduzir a menção à vida de um boi nós conseguimos localizar mais precisamente o que está sendo abandonado dessa vida. As atividades de cognição e o prazer obtido com elas são distintivos de uma 
vida humana, sem elas estamos nos entregando a um tipo de vida incompleto e insatisfatório.

A pessoa que escolhesse viver uma tal vida é alguém que não se frustra em não poder ter nenhum prazer cognitivo (note que Aristóteles não exige atividades cognitivas muito sofisticadas, podem ser aquelas relacionadas aos sentidos). Mas que pessoa é essa, podemos nos perguntar, que não sente frustração com isso? É alguém com quem realmente queremos e podemos discutir suas opiniões sobre a melhor vida? Não se trata apenas de desprezá-lo por fazer escolhas inferiores. Se trata mesmo de não entender as opções de uma tal pessoa ${ }^{15}$.

O último cenário apresenta o seguinte:

Semelhantemente, tampouco pelo prazer do sono, pois em que difere dormir um sono indesperto do primeiro dia até o último de mil anos ou quantos forem e viver sendo um vegetal? Os vegetais parecem participar de uma vida desse tipo, assim como os embriões. Também esses, com efeito, seguem crescendo (desde a primeira gênese na mãe), mas dormindo o tempo todo. Desse modo, é evidente, a partir dessas coisas, que escapa aos que investigam o que é o bem viver e o que é o bem no viver. (1216a2-10)

No último cenário, Aristóteles pede que se considere uma vida em que fosse desfrutado um único prazer: o de dormir. Esta ideia pode parecer estranha, mas dormir é prazeroso. Ele traz relaxamento após o esforço. Todavia, a vida de alguém adormecido é uma em que suas atividades típicas permanecem em potência. Desfrutar somente deste prazer, portanto, corresponderia a não ter uma vida ativa. Poderia ser essa uma vida satisfatória e uma que alguém desejaria viver ao invés de não vivê-la? Há aqui outro 
aspecto importante. Como vimos, em cada uma das situações anteriores, a escolha de não viver parecia sempre uma escolha radical, deixando-nos em dúvida se afinal mesmo que insatisfatória a vida por si mesma ainda valesse de alguma forma a pena. Ora, alguém que passe a vida dormindo desfruta precisamente da condição da vida despida de toda atividade intencional. Com efeito, a vida mencionada dos embriões e dos vegetais é precisamente essa. $\mathrm{O}$ sono ali é um sono desprovido de intencionalidade. Assim, é ainda diferente do prazer que temos ao dormir, pois temos prazer por dormir justamente porque acordamos. A ideia de uma vida de vegetal é aquela de um sono indesperto. É essa vida desejável no sentido de plenamente satisfatória para alguém?

Como no cenário anterior, se alguém disser que é, podemos questionar se devemos seriamente considerar sua opinião para determinar o que é a vida boa, sendo a de alguém que não se importa de levar uma vida que mais se assemelha a de um vegetal do que a de um outro de nós, seres humanos.

Não é em todos os cenários evidente, como no dois últimos, que no caso da escolha por viver uma vida desprovida de um desses tipos de prazeres, associados como estão a atividades ou desejos tipicamente humanos, isto equivaleria a querer levar a vida de um outro tipo de ser. É, entretanto, comum em todos os cenários que a escolha seja entre levar uma vida menos do que humanamente satisfatória e não levá-la. $\mathrm{O}$ exercício é desenhado para abrir nossos olhos para isso.

Qual a moral dessa história? Uma vida satisfatória não é composta apenas por satisfação subjetiva, isto é, da satisfação com o que quer que seja. Obtemos satisfação com 
algumas coisas de natureza determinada e determinadas por nossa natureza humana. Nesta medida, a satisfação plena dos nossos desejos é a realização de algo - de uma natureza determinada - ao contrário do que uma versão subjetivista da satisfação plena de nossos desejos compreenderia. É nessa compreensão do prazer que podemos entender o apelo ao ergon humano como algo que razoavelmente explica por que uma vida sem certos tipos de atividades e prazeres a elas relacionadas é insatisfatória.

Abstract: This paper takes as its starting point the argument from Eudemian Ethics (EE) II, 1 which introduces as premisses conclusions from the previous chapters, namely, (i) the chief good of human beings is an end and (ii) everybody judges speculative wisdom, moral virtue and pleasure to be ends, either all or some of them. These two claims allow Aristotle to conclude that the most desirable of all goods is in the soul and to proceed arguing to his main conclusion in terms of the ergon, function or characteristic activity, of the soul. It should be noticed, though, that if the ergon of the human soul can explain speculative wisdom and moral virtues to be ends, the same is not so easily defensible in the case of pleasure. In fact, to take pleasure as end seems to take a subjective satisfaction with no matter what as end. Now, the ergon of the soul cannot explain pleasure as an end in this unrestricted way. To solve this difficulty, this paper seeks to interpret a prior passage, I, 5, $1215 \mathrm{~b} 15-1216 \mathrm{a} 10$, as responsible for restricting the range of pleasures that can be counted as finalities to human beings.

Keywords: Aristotle; Eudemian Ethics; pleasure; ergon.

\section{REFERÊNCIAS}

Edições e traduções das obras de Aristóteles

BYWATER, I. 1942. Ethica Nicomachea. Oxford, Clarendon.

INWOOD, B.; WOOLF, R. 2013. Eudemian Ethics. Cambridge, Cambridge U. P.

KENNY, A. 2011. The Eudemian Ethics. Oxford, Oxford 
U. P.

SUSEMIHL, F. Aristotelis Ethica Eudemia, Eudemii Rhodii Ethica. Leipzig: Teubner, 1884.

WALZER, R. R.; MINGAY, J. M. 1991. Ethica Eudemia. Oxford, Clarendon.

Outras obras

BARNEY, B., "Aristotle's Argument for a Human Function", Oxford Studies in Ancient Philosophy, v.34, 2008, pp.293-322.

BUDDENSIEK, F. 1999. Die Theorie des Glücks in Aristoteles' Eudemischer Ethik. Göttingen, Vandenhoeck \& Ruprecht.

DIRLMEIER, F. 1984. Eudemische Ethik. Berlin, Akademie-Verlag.

FINNIS, J. Fundamental os Ethics, Washington: Georgetown University Press, 1983.

GIGON, O. 1971. "Das Prooimion der EE". In: MORAUX, P.; HARLFINGER, D. Untersuchungen zur Eudemischen Ethik. Berlin, Walter de Gruyter.

NUSSBAUM, M. "Aristotle on Human Nature and the Foundations of Ethics," in ALTHAM, J.E.J.; HARISSON, R. (org), World, Mind, and Ethics: Essays on the Ethical Philosophy of Bernard Williams, Cambridge: Cambridge University Press, 1995.

WHITING, J., "The pleasure of thinking together", in LEIGH, F, The Eudemian Ethics on the Voluntary, 
Friendship, and Luck. Brill: Boston, 2012, pp.77-154.

ZILLIG, R., "O fim com vistas ao qual um homem escolhe viver (Ética Eudêmia I 5, 1215b15-16a10), Dois Pontos, v.10, n.2, 2013, pp.357-374. 